\title{
Plant Cultivation Driver with Update Environmental Parameters
}

\author{
Hau-Chen Yen, ${ }^{1}$ Hung-Liang Cheng, ${ }^{2 *}$ Yi-Yu Lu, ${ }^{1}$ Fu-Chieh Yang, ${ }^{3}$ and Sin-Yu Chen ${ }^{4}$ \\ ${ }^{1}$ Department of Electrical Engineering, Far-East University, Tainan 74448, Taiwan \\ ${ }^{2}$ Department of Electrical Engineering, I-Shou University, Kaohsiung 84001, Taiwan \\ ${ }^{3}$ Biotechnology Center in Southern Taiwan, Academia Sinica, Tainan 74145, Taiwan \\ ${ }^{4}$ Department of Electrical Engineering, National Ilan University, Yilan 26047, Taiwan
}

(Received December 3, 2019; accepted May 6, 2020)

Keywords: Arduino chip, light-emitting diode (LED), power factor, ultrasonic atomizer

Good plant growth is ensured by suitable light source, temperature, humidity, carbon dioxide content, moisture, and nutrient conditions. In this paper, a plant cultivation driver system that consists of artificial light sources, ultrasonic nebulizers, and ventilation fans is proposed. By using the control scheme of pulse-width modulation, the output powers of the artificial light sources, the ultrasonic nebulizers, and the fans are adjusted. The artificial light sources use red, green, and blue light-emitting diodes (LEDs) to provide photosynthetic energy to plants. The ultrasonic nebulizers used for humidity control are installed near the plants to provide fine water molecules needed for plant leaves, and the fans provide them the desired temperature and venting environment. The driver uses the Arduino chip connected to the light, temperature, and humidity sensors to monitor these environmental parameters. Based on the environmental conditions fed back from the sensors, the chip can provide suitable growth conditions for plants by respectively controlling the light sources, atomizers, and fans. A $500 \mathrm{~W}$ prototype driver with update environmental parameters was designed and built. The output power range was adjusted from 60 to $460 \mathrm{~W}$ to meet plant growth requirements. The measured input power factor was higher than 0.92 , and the highest conversion efficiency of the driver was $82.5 \%$.

\section{Introduction}

Smart agriculture is a newly emerging trend that uses sensor technology, intelligent machine equipment, Internet of Things, big data analysis, and so forth to replace the timing controller to provide a favorable growth environment. ${ }^{(1-5)}$ On the other hand, global warming caused by the depletion of fossil fuels will frequently induce extreme weather anomalies that may hinder plant growth and lead to human food shortage. ${ }^{(6-8)}$ Recently, plant factories have been controlled to establish an environment suitable for plant growth, thereby protecting plants from extreme weather. ${ }^{(9-15)}$ The light intensity, light wavelength, light on/off cycle, temperature, and humidity required by plants differ at different stages, such as seeding, growth, and flowering. ${ }^{(16-20)}$ Therefore, an energy driver should be designed to provide different environmental conditions at different stages of plant growth.

\footnotetext{
*Corresponding author: e-mail: hlcheng@isu.edu.tw
}

https://doi.org/10.18494/SAM.2020.2722 
To create a suitable environmental condition in plant factories, the commercial environmental control system should consist of many environmental monitoring and control sets to adjust temperature, humidity, light, and so on. However, the light sources, temperature, and humidity are individually controlled in these plant factories. The light source, atomizer, and fan must use separate power converters. Besides, these converters require different controllers to regulate light, temperature, and humidity. This leads to an increase in the cost of circuit components. In addition, the parameters set to control the growth environment remain unchanged during plant growth, resulting in the waste of energy in the plant factory. To solve these problems, in this study, an innovative approach to control environment conditions simultaneously by a single control device is proposed. A driver system that connects light, temperature, and humidity sensors to an Arduino chip for the detection of plant growth environmental conditions is designed. By controlling the light source, ultrasonic atomizer, and ventilation fan, the driver system can provide a suitable environment for plant growth. ${ }^{(21-23)}$ This paper is organized as follows. Section 2 describes the concept of the proposed driver. Section 3 details the analysis of the circuit and the derivation of equations. The design and experimental test of a $500 \mathrm{~W}$ prototype circuit are provided in Sect. 4. Finally, some conclusions are given in Sect. 5.

\section{Circuit Configuration}

Figure 1 shows the schematic diagram of the proposed plant driver system. The shelves are used to improve plant utilization in the plant factory. Plants are distributed throughout the shelves. To increase plant growth efficiency, a number of devices that provide light, humidity, and temperature control are placed around the shelves to provide a suitable environment for the plants. As shown in Fig. 1, a power factor corrector (PFC) is used to achieve high power factor and low total current harmonic distortion (THDi). The PFC outputs a de voltage to all flyback converters that are connected in parallel at input terminals. Each flyback converter supplies a stable dc voltage for each shelf. These flyback converters are controlled by the Arduino IC to control ambient devices, such as light sources, ultrasonic nebulizers, and fans. The suitable environmental conditions for plants can be found in the literature and/or be obtained on the

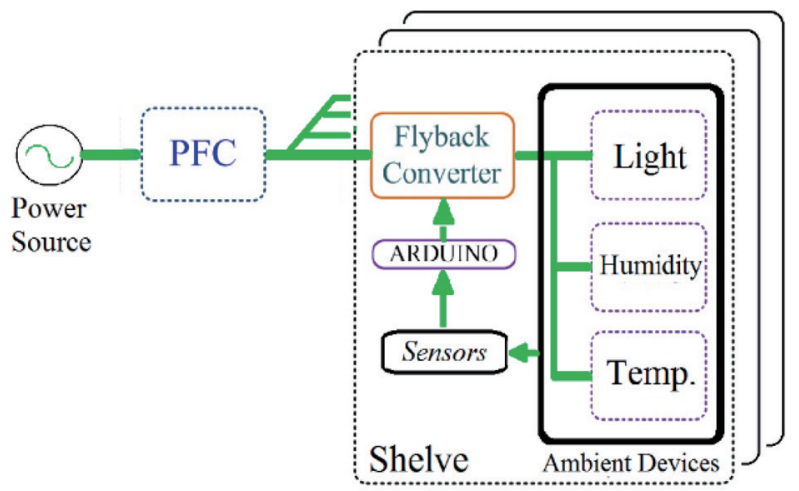

Fig. 1. (Color online) Schematic diagram of the proposed plant driver system. 
basis of previous experimental results. ${ }^{(16-20)}$ The energy supplied from the flyback converters to the ambient devices is adjusted on the basis of sensor feedback to ensure that the environment is suitable for plants in different growth stages.

A boost converter is adopted to serve as the front-end PFC, as shown in Fig. 2. The boosttype PFC is composed of a bridge rectifier $B D$, an inductor $L_{B}$, an active switch $S_{B}$, a diode $D_{1}$, and a bulky capacitor $C_{d c}$. The PFC uses the control scheme of error multiplication. The product of the sampled input voltage and the error voltage between the output voltage and the reference voltage is compared with the inductor current to determine the turn-off time of the active switch. In addition, the PFC is controlled to operate in the boundary operation mode. In other words, once the inductor current is reduced to zero, the active switch is turned on. In this manner, the input current is wave-shaped into a sinusoidal waveform and is in phase with the input voltage source. This ensures a high power factor and a low THDi.

The second stage that powers the environmental control device is a flyback converter, which has a relatively simple circuit topology compared with other dc/dc converters for low power applications. Each flyback transformer can serve the dual purpose of energy storage/release and galvanic isolation. Figure 3 shows the circuit topology of the flyback converter whose transformer consists of a primary winding and several secondary windings. The primary winding is connected to a high-frequency-driven switch $S_{m}$. Each secondary winding is connected in series with an independent low-frequency-driven switch $\left(S_{1}-S_{n}\right)$ for energy transfer. A high-frequency signal $v_{G S m}$ and a plurality of low-frequency signals $\left(v_{G S 1}-v_{G S n}\right)$ are output by the Arduino IC. These signals are fed to isolated gated driver integrated circuits (IC) to turn these active switches on and off. The Arduino IC is a widely used microcontroller because it requires little programming or electronics knowledge and is easy to interface with various sensors. The Arduino IC is programmable and can be easily modified. It records the environmental parameters required for plant growth. When observing that the plant is about to enter the next stage of growth, the code for the corresponding growth stage is typed into the Arduino IC to match the environmental parameters.

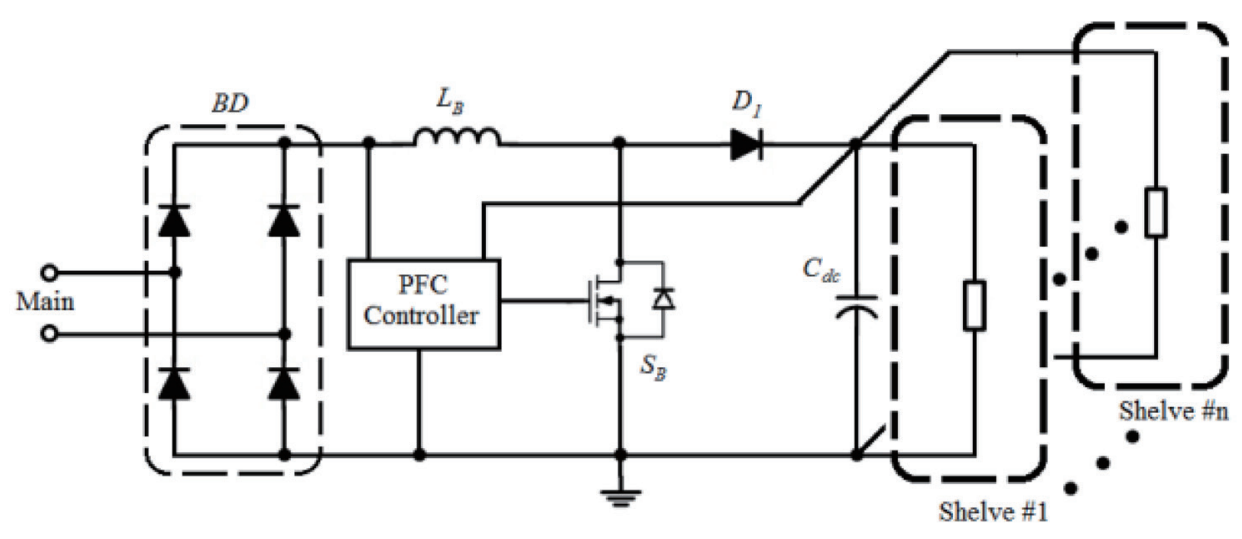

Fig. 2. Schematic of boost-type PFC. 


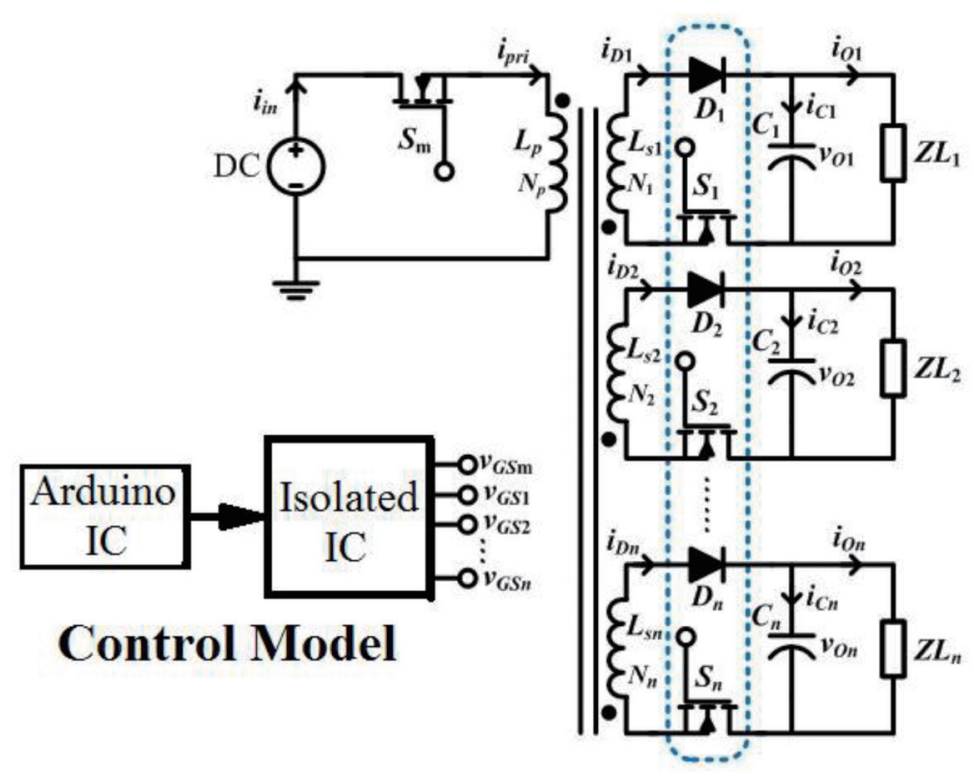

Fig. 3. (Color online) Arduino IC-controlled flyback converter.

\section{Environmental Parameter Control Mechanism}

The magnetic flux in the transformer of the flyback converter must be balanced at steadystate operation. The energy stored on its primary side must be completely transferred to the secondary side to prevent core saturation. By adjusting each turn-on time of each lowfrequency switch on the secondary side to match the turn-on time of the active switch of the primary side, the energy transferred from the primary side to the secondary side can be correctly supplied to each load.

Figure 4 shows red, blue, and green light-emitting diode (LED) loads, where the flyback converter is designed to work in the discontinuous current mode (DCM). To simplify the circuit analysis, the following assumptions are made:

(1) All circuit components are ideal.

(2) The output capacitors $C_{1}-C_{3}$ are large enough to regard the output voltages $V_{O 1}-V_{O 3}$ as constant.

(3) The coupling coefficient between the primary and secondary windings is equal to one. Hence, there is no leakage inductance in the transformer.

Figure 5 shows the timing diagram designed to control the LED brightness. The blue, green, and red LEDs are controlled by $S_{1}, S_{2}$, and $S_{3}$, respectively. In order, the brightest, second brightest, and lowest brightness LEDs are blue, green, and red, respectively. The switches $S_{1}$ to $S_{3}$ are turned on and off at a low frequency with the switching period $T_{L}$, while the switch $S_{m}$ is turned on and off at a high frequency with the switching period $T_{H}$. The duty cycle $D_{H}$ of the switch $S_{m}$ varies with the number of low-frequency switches that are turned on. When all the switches $S_{1}$ to $S_{3}$ are turned on, the duty ratio $D_{H 1}$ of the switch $S_{m}$ is maximum. In contrast, 


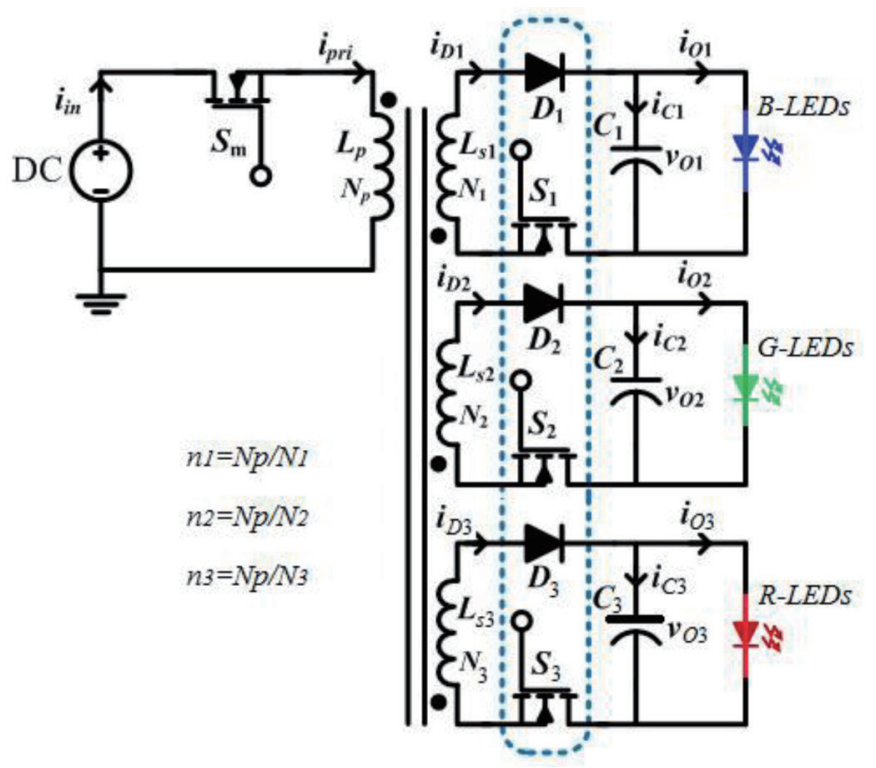

Fig. 4. (Color online) Flyback converter with LED loads.

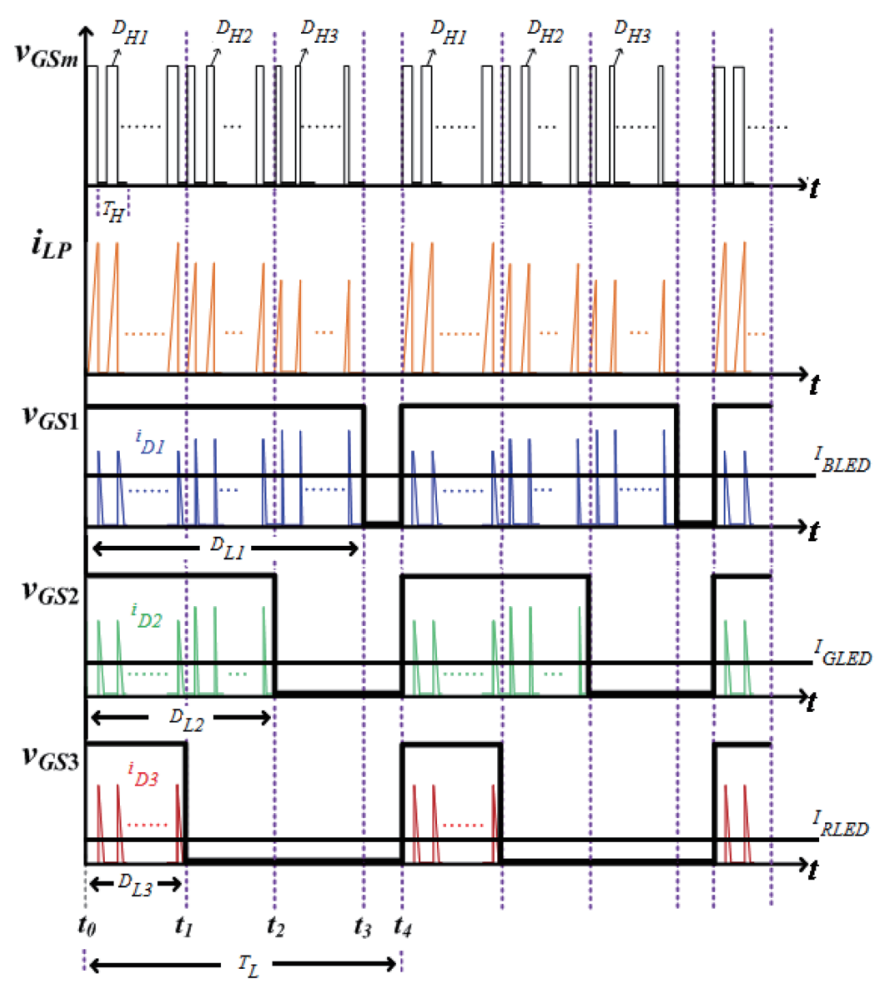

Fig. 5. (Color online) Timing diagram.

during $t_{1}$ to $t_{2}$, only the blue and green LEDs are lit. In this case, the duty ratio of $S_{m}$ should be reduced to a lower value $\left(D_{H 2}\right)$ to prevent the transfer of excessive energy to the secondary winding from the primary side, thereby burning the LED. 
During $t_{0}$ to $t_{1}$, all the LEDs are lit. The circuit operation can be divided into three operation modes in each high-frequency cycle in the steady state. Figure 6 shows the equivalent circuits of the different operation modes and Fig. 7 shows the theoretical voltage and current waveforms of the key components.

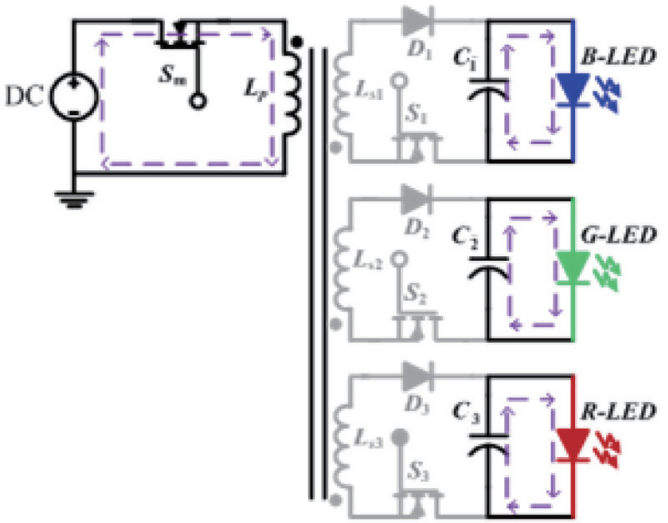

(a)
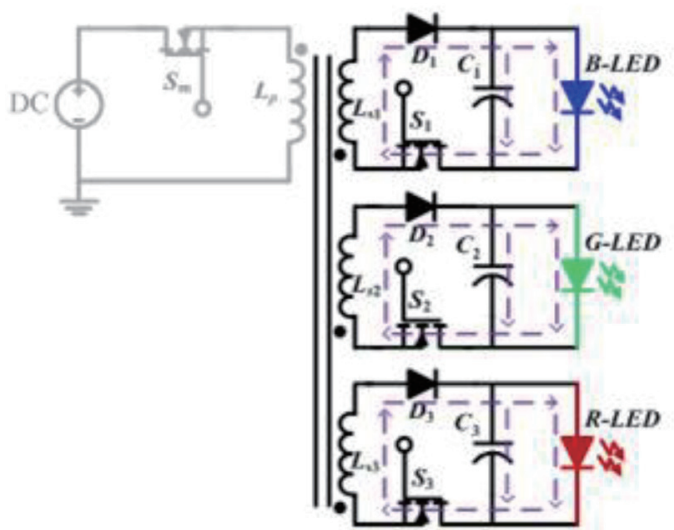

(b)
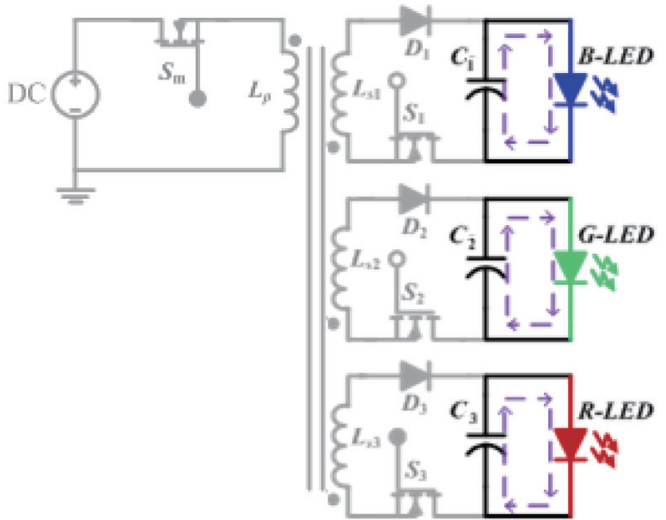

(c)

Fig. 6. (Color online) Operation modes. (a) Mode I. (b) Mode II. (c) Mode III.

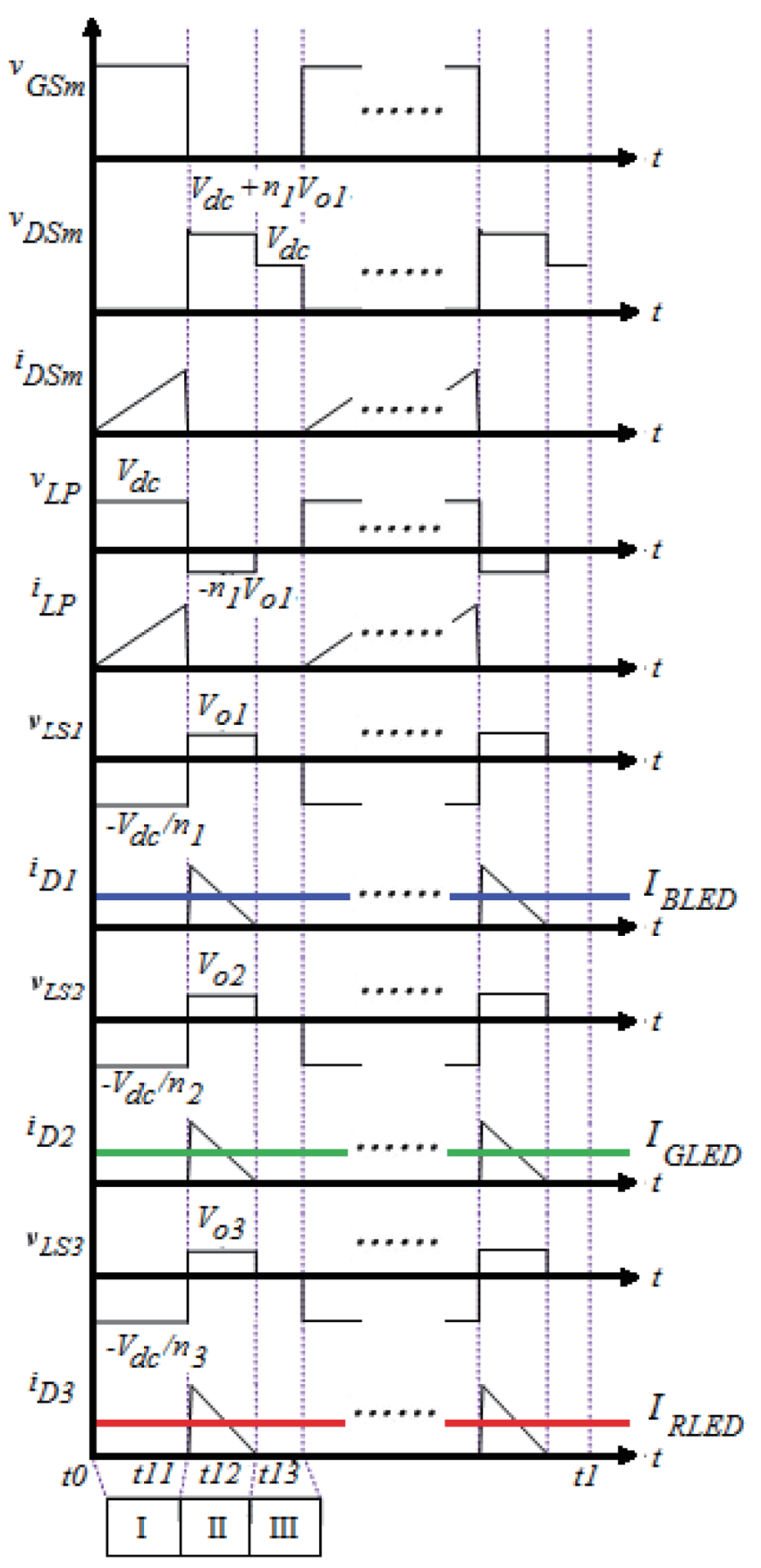

Fig. 7. (Color online) Theoretical waveforms. 
The LEDs are dimmed by the control scheme of low-frequency modulation, as shown in Fig. 5. In other words, each LED is turned on at its rated current and its average current is equal to the low-frequency duty cycle. Plants at different growth stages require different LED light intensities. Therefore, the intensities of the red, green, and blue LEDs must be adjusted accordingly. According to the pattern in Fig. 5, the average currents of the blue, green, and red LEDs are denoted as $I_{B L E D}, I_{G L E D}$, and $I_{R L E D}$, and can be expressed as

$$
\begin{aligned}
& I_{B L E D}=\frac{t_{3}-t_{o}}{t_{4}-t_{o}} \times I_{B(\text { Rated })}, \\
& I_{G L E D}=\frac{t_{2}-t_{o}}{t_{4}-t_{o}} \times I_{G(\text { Rated })}, \\
& I_{R L E D}=\frac{t_{1}-t_{o}}{t_{4}-t_{o}} \times I_{R(\text { Rated })},
\end{aligned}
$$

where $I_{B(\text { Rated })}, I_{G(\text { Rated) }}$, and $I_{R(\text { Rated })}$ are the rated currents of the blue, green, and red LEDs, respectively.

The flyback converter is operated in DCM and supplies multiple sets of loads simultaneously. The design equations of the circuit components are shown as

$$
\begin{gathered}
L_{p}=\frac{\eta V_{d c}^{2} D_{H(\max )}^{2}}{2 \sum_{i=1}^{n} P_{o i} f_{H}}, \\
n_{i}=\frac{V_{d c}}{V_{o i}} \cdot \frac{D_{H(\max )}}{1-D_{H(\max )}}=\frac{N_{p}}{N_{i}}, \\
L_{s i}=\frac{L_{p}}{n_{i}^{2}}, \\
D_{G S m}=\sqrt{\frac{2 L_{p} f_{H} \sum_{i=1}^{n} P_{o i}}{\eta V_{d c}^{2}}},
\end{gathered}
$$

where $\eta$ is the converter efficiency, $V_{d c}$ is the DC input voltage, $f_{H}$ is the switching frequency of $S_{m}, D_{H(\max )}$ is the maximum duty cycle of $S_{m}, P_{o}$ is the load rated power, $n_{i}(i=1,2$, and 3$)$ is the turn ratio of the transformer, $L_{p}$ is the transformer primary inductance, $L_{s i}$ is the transformer $i$-th secondary inductance, and $D_{G S m}$ is the duty cycle of $S_{m}$.

When the loads in Fig. 3 are changed to an ultrasonic atomizer module or a fan module, the operation modes are similar to those with the LED loads. All of these modules are driven 
by direct current. The description will not be repeated here. Ultrasonic atomizers are used to provide space humidity, and fans are used to provide airflow in the space to promote plant growth.

\section{Design and Experimental Test Results}

A prototype circuit was built and tested. Each LED string consists of twenty $1 \mathrm{~W}$ LEDs connected in series. The circuit specifications and the component parameters obtained by using Eqs. (4)-(7) are shown in Table 1. The LEDs are dimmed by controlling the duty cycles of the low-frequency switches. Table 2 shows all possible conditions, depending on whether each LED string is turned on or off. Under each condition, the duty ratio of the switch $S_{m}$ and the input and output powers are measured, and the conversion efficiency is calculated.

In the design of flyback converters for driving ultrasonic nebulizers and ventilation fans, the architecture in Fig. 3 is still used. The loads are three $20 \mathrm{~W}$ ultrasonic atomizers and one $2 \mathrm{~W}$ DC fan, which is controlled to slowly rotate to prevent damage to the plants. The component parameters are shown in Table 3. The duty ratio of the switch $S_{m}$ and the circuit conversion efficiency for all the conditions for the three ultrasonic atomizers and the DC fan that are either on or off are shown in Table 4.

Table 1

Circuit specifications and component parameters.

\begin{tabular}{|c|c|c|c|}
\hline DC voltage $V_{d c}$ & & $240 \mathrm{~V}_{\mathrm{dc}}$ & \\
\hline Switching frequency $f_{H}$ & & $32 \mathrm{kHz}$ & \\
\hline Max. duty ratio $D_{H}$ & & 0.2 & \\
\hline Switching frequency $f_{L 1}-f_{L 3}$ & & $1 \mathrm{kHz}$ & \\
\hline Max. duty ratio $D_{L 1}-D_{L 3}$ & & 1 & \\
\hline Primary inductance $L_{p}$ & & $571 \mu \mathrm{H}$ & \\
\hline Output voltage $V_{o i}$ & $\mathrm{~B}: 60 \mathrm{~V}_{\mathrm{dc}}$ & $\mathrm{G}: 58 \mathrm{~V}_{\mathrm{dc}}$ & $\mathrm{R}: 42 \mathrm{~V}_{\mathrm{dc}}$ \\
\hline Output current $I_{o i}$ & B: $0.34 \mathrm{~A}$ & G: $0.35 \mathrm{~A}$ & $\mathrm{R}: 0.48 \mathrm{~A}$ \\
\hline LED equivalent resistance $r_{o i}$ & B: $176.5 \Omega$ & G: $165.7 \Omega$ & $\mathrm{R}: 87.5 \Omega$ \\
\hline Turn ratio $n_{i}=N_{p} / N_{i}$ & B: 1.00 & G: 1.00 & $\mathrm{R}: 1.35$ \\
\hline Output capacitance $C_{i}$ & B: $100 \mu \mathrm{H} / 250 \mathrm{~V}$ & G: $100 \mu \mathrm{H} / 250 \mathrm{~V}$ & $\mathrm{R}: 100 \mu \mathrm{H} / 250 \mathrm{~V}$ \\
\hline Secondary inductance $L_{s i}$ & B: $571 \mu \mathrm{H}$ & G: $571 \mu \mathrm{H}$ & $\mathrm{R}: 310 \mu \mathrm{H}$ \\
\hline
\end{tabular}

Table 2

Conversion efficiency under different light conditions.

\begin{tabular}{ccccccc}
\hline B-LED & G-LED & R-LED & $D_{G S m}(\%)$ & $P_{o}(\mathrm{~W})$ & $P_{\text {in }}(\mathrm{W})$ & $\eta(\%)$ \\
\hline ON & ON & ON & 19.54 & 61.77 & 72.00 & 85.8 \\
ON & ON & OFF & 16.52 & 44.26 & 51.84 & 85.4 \\
ON & OFF & ON & 14.43 & 38.15 & 41.52 & 91.9 \\
ON & OFF & OFF & 10.62 & 20.64 & 24.72 & 83.5 \\
OFF & ON & ON & 16.35 & 41.13 & 48.72 & 84.4 \\
OFF & ON & OFF & 11.62 & 23.62 & 28.80 & 82.0 \\
OFF & OFF & ON & 9.70 & 17.51 & 20.40 & 85.8 \\
OFF & OFF & OFF & 0 & 0 & 0 & 0 \\
\hline
\end{tabular}


Table 3

Component parameters with ultrasonic atomizers and fan loads.

\begin{tabular}{|c|c|c|c|c|}
\hline DC voltage $V_{d c}$ & \multicolumn{4}{|c|}{$240 \mathrm{~V}_{\mathrm{dc}}$} \\
\hline Switching frequency $f_{H}$ & \multicolumn{4}{|c|}{$32 \mathrm{kHz}$} \\
\hline Max. duty ratio $D_{H}$ & \multicolumn{4}{|c|}{0.2} \\
\hline Switching frequency $f_{L 1}-f_{L 4}$ & \multicolumn{4}{|c|}{$1 \mathrm{kHz}$} \\
\hline Max. duty ratio $D_{L 1}-D_{L 4}$ & \multicolumn{4}{|c|}{1} \\
\hline Output capacitance $C_{i}$ & \multicolumn{4}{|c|}{$100 \mu \mathrm{H} / 250 \mathrm{~V}$} \\
\hline Primary inductance $L_{p}$ & \multicolumn{4}{|c|}{$559 \mu \mathrm{H}(47 \mathrm{~T})$} \\
\hline Output voltage $V_{o i}$ & $V_{o 1}: 30.7 \mathrm{~V}_{\mathrm{dc}}$ & $V_{o 2}: 29.8 \mathrm{~V}_{\mathrm{dc}}$ & $V_{o 3}: 30.3 \mathrm{~V}_{\mathrm{dc}}$ & $V_{o 4}: 28.0 \mathrm{~V}_{\mathrm{dc}}$ \\
\hline Output current $I_{o i}$ & $I_{o 1}: 0.631 \mathrm{~A}$ & $I_{o 2}: 0.594 \mathrm{~A}$ & $I_{o 3}: 0.623 \mathrm{~A}$ & $I_{o 4}: 0.062 \mathrm{~A}$ \\
\hline Equivalent resistance $r_{o i}$ & $r_{o 1}: 48.7 \Omega$ & $r_{o 2}: 50.1 \Omega$ & $r_{o 3}: 48.6 \Omega$ & $r_{o 4}: 452 \Omega$ \\
\hline Turn ratio $n_{i}=N_{p} / N_{i}$ & $n_{1}: 2.2$ & $n_{2}: 2.2$ & $n_{3}: 2.2$ & $n_{4}: 2.6$ \\
\hline Secondary inductance $L_{s i}$ & $L_{S 1}: 114 \mu \mathrm{H}(21 \mathrm{~T})$ & $L_{S 2}: 110 \mu \mathrm{H}(21 \mathrm{~T})$ & $L_{s 3}: 112 \mu \mathrm{H}(21 \mathrm{~T})$ & $L_{s 4}: 94.3 \mu \mathrm{H}(18 \mathrm{~T})$ \\
\hline
\end{tabular}

Table 4

Conversion efficiency with ultrasonic atomizers and fan.

\begin{tabular}{ccclcccc}
\hline Atomizer \#1 & Atomizer \#2 & Atomizer \#3 & Fan & $D_{G S m}(\%)$ & $P_{o}(\mathrm{~W})$ & $P_{\text {in }}(\mathrm{W})$ & $\eta(\%)$ \\
\hline ON & ON & ON & ON & 17.22 & 57.67 & 60.96 & 94.6 \\
ON & ON & ON & OFF & 17.00 & 55.94 & 59.28 & 94.4 \\
ON & ON & OFF & ON & 14.13 & 38.80 & 42.96 & 90.3 \\
ON & ON & OFF & OFF & 13.90 & 37.07 & 41.76 & 88.8 \\
ON & OFF & ON & ON & 14.08 & 40.10 & 42.72 & 93.9 \\
ON & OFF & ON & OFF & 13.84 & 38.24 & 41.04 & 93.2 \\
ON & OFF & OFF & ON & 10.29 & 21.10 & 24.48 & 86.2 \\
ON & OFF & OFF & OFF & 10.04 & 19.37 & 22.80 & 85.0 \\
OFF & ON & ON & ON & 13.88 & 38.30 & 41.28 & 92.8 \\
OFF & ON & ON & OFF & 13.67 & 36.57 & 39.36 & 92.9 \\
OFF & ON & OFF & ON & 10.06 & 19.61 & 23.04 & 85.1 \\
OFF & ON & OFF & OFF & 9.60 & 17.70 & 20.88 & 84.8 \\
OFF & OFF & ON & ON & 9.90 & 20.63 & 22.32 & 92.4 \\
OFF & OFF & ON & OFF & 9.50 & 18.87 & 20.40 & 92.5 \\
OFF & OFF & OFF & ON & 2.00 & 1.73 & 2.40 & 72.1 \\
OFF & OFF & OFF & OFF & 0 & 0 & 0 & 0 \\
\hline
\end{tabular}

A $480 \mathrm{~W}$ boost-type PFC is designed and built to drive six sets of LED loads (as shown in Table 1) and two sets of ultrasonic atomizer and fan loads (as shown in Table 3). The eight primary switches of the eight circuits are connected to the 8-digit pins in the Arduino of Mega 2560 , and the 26 ON/OFF pins in the Arduino are connected to the 26 switches of the secondary side. The 26 switches are used to control the energy delivered to the load. Table 5 shows the specifications of the PFC circuit and the detailed component parameters can be seen in Fig. 8. Table 6 shows the power factor and conversion efficiency under different output powers. The proposed drive system architecture can be applied to provide environmental conditions without having to significantly change the system structure for different plants. Although this circuit is cost-effective in the high power range, it is less cost-effective in the low-power range owing to the addition of PFC power stages and control circuitry. However, its energy supply is adjusted during the growth stages of plants and energy waste is effectively reduced. 
Table 5

Circuit specifications of boost-type PFC.

\begin{tabular}{lc}
\hline AC source $V_{S}$ & AC $110 \mathrm{Vrms} / 60 \mathrm{~Hz}$ \\
DC-link power $P_{o}$ & $480 \mathrm{~W}$ \\
DC-link voltage $V_{d c}$ & $240 \mathrm{~V}$ \\
DC-link current $I_{o}$ & $0.25-1.9 \mathrm{~A}$ \\
\hline
\end{tabular}

Table 6

Conversion efficiency and power factor.

\begin{tabular}{rccc}
\hline$P_{o}(\mathrm{~W})$ & $P_{S}(\mathrm{~W})$ & $\eta(\%)$ & $P F$ \\
\hline 63.5 & 109.5 & 58.0 & 0.921 \\
89.5 & 127.6 & 70.1 & 0.948 \\
120.0 & 170.0 & 70.6 & 0.966 \\
154.0 & 213.5 & 72.1 & 0.969 \\
183.8 & 252.4 & 72.8 & 0.971 \\
214.4 & 290.4 & 73.8 & 0.973 \\
244.0 & 320.7 & 76.1 & 0.980 \\
273.9 & 368.7 & 74.3 & 0.982 \\
302.6 & 414.5 & 73.0 & 0.981 \\
344.7 & 417.9 & 82.5 & 0.983 \\
377.0 & 461.1 & 81.8 & 0.981 \\
407.6 & 503.4 & 81.0 & 0.980 \\
442.1 & 556.6 & 79.4 & 0.979 \\
459.4 & 597.8 & 76.8 & 0.982 \\
\hline
\end{tabular}

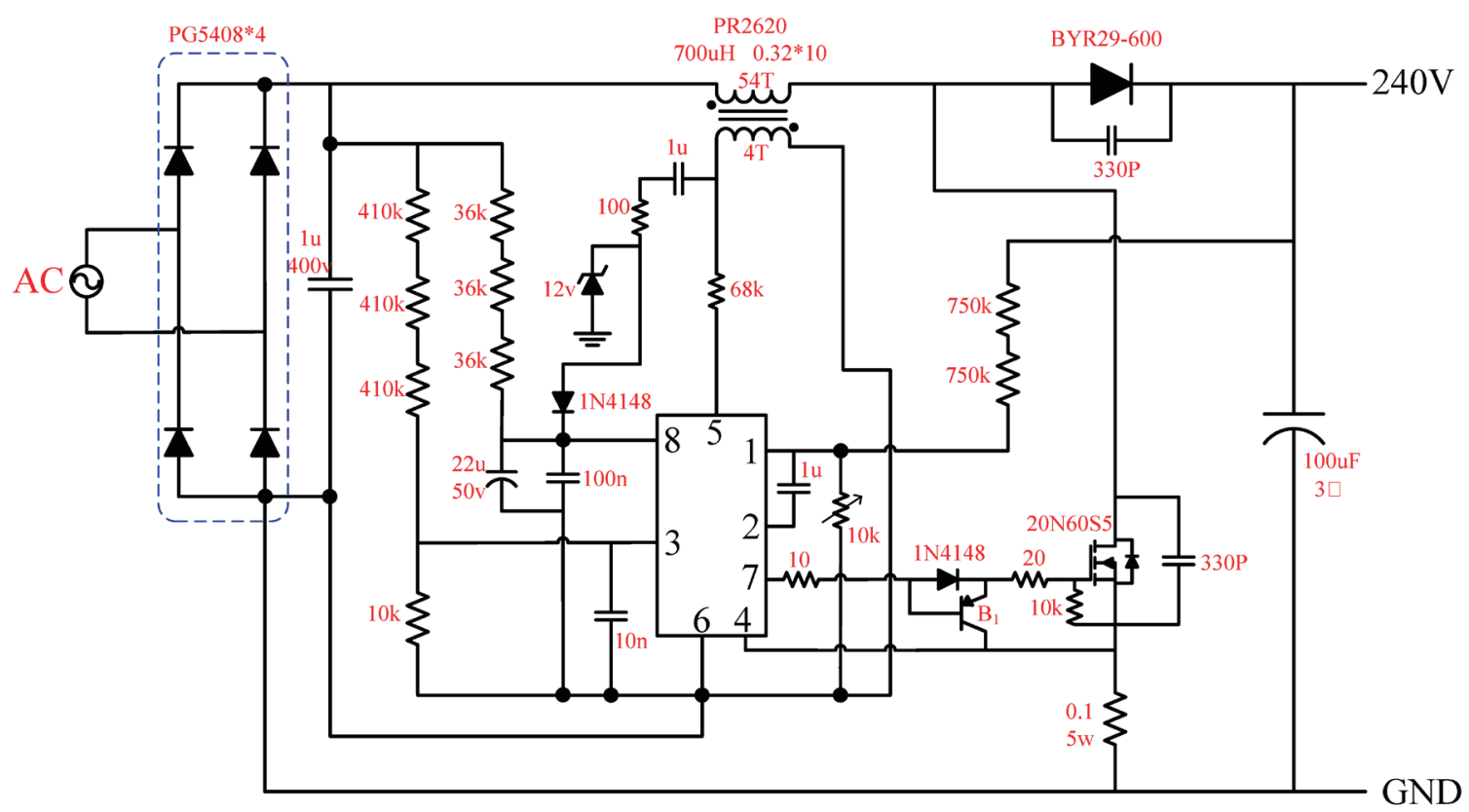

Fig. 8. (Color online) Boost-type PFC.

\section{Conclusions}

A plant cultivation driver system for driving artificial light sources, ultrasonic nebulizers, and ventilation fans is proposed in this paper. The green, blue, and red high-brightness LEDs serve as light sources. The circuit topology consists of a boost converter serving as PFC and eight flyback converters used to drive LEDs, ultrasonic nebulizers, and ventilation fans. These 
devices are well controlled by the Arduino IC to provide suitable environmental conditions for plants at different growth stages. A $500 \mathrm{~W}$ prototype driver was built and tested. The output power range was adjusted from 60 to $460 \mathrm{~W}$. The measured input power factor was higher than 0.92 , and the conversion efficiency of the driver was $82.5 \%$.

\section{References}

1 G. N. Rameshaiah, J. Pallavi, and S. Shabnam: Int. J. Eng. Res. Gen. Sci. 3 (2015) 314. http://citeseerx.ist.psu. edu/viewdoc/summary?doi=10.1.1.679.756

2 T. K. Fan: J. Convergence Inf. Technol. (JCIT) 8 (2013) 4728. https://doi.org/10.4156/jcit.vol8.issue2.26

3 O. Elijah, T. A. Rahman, I. Orikumhi, C. Y. Leow, and M. N. Hinfia: IEEE Internet Things J. 5 (2018) 3758. https://doi.org/10.1109/JIOT.2018.2844296

4 H. Channe, S. Kothari, and D. Kadam: Int. J. Comput. Technol. Appl. 6 (2015) 374. https://www. semanticscholar.org/paper/Multidisciplinary-Model-for-Smart-Agriculture-using-Channe-Kothari/ e914d431520f4cb60b9d80b123f7d43782claba8

5 C. Perera, A. Zaslavsky, P. Christen, and D. Georgakopoulos: Trans. Emerging Telecommun. Technol. 25 (2014) 81. https://doi.org/10.1002/ett.2704

6 K. Wolter and M. S. Timlin: Int. J. Climatol. 31 (2011) 1074. https://rmets.onlinelibrary.wiley.com/doi/ full/10.1002/joc. 2336

7 H. Charles, J. Godfray, J. R. Beddington, I. R. Crute, L. Haddad, D. Lawrence, J. F. Muir, J. Pretty, S. Robinson, S. M. Thomas, and C. Toulmin: Science 327 (2010) 812. https://doi.org/10.1126/science.1185383

8 J. Ingram: Food Secur. 3 (2011) 417. https://doi.org/10.1007/s12571-011-0149-9

9 T. Kozai: Proc. Jpn. Academy, Series B (2013) 447. https://doi.org/10.2183/pjab.89.447

10 K. Kato, R. Yoshida, A. Kikuzaki, T. Hirai, H. Kuroda, K. Hiwasa-Tanase, K. Takane, H. Ezura, and T. Mizoguchi: J. Agric. Food Chem. 58 (2010) 9505. https://doi.org/10.1021/jf101874b

11 H. Shimizu, Y. Saito, H. Nakashima, J. Miyasaka, and K. Ohdoi: Proc. 18th World Congress: The International Federation of Automatic Control. (2011) 605. https://doi.org/10.3182/20110828-6-IT-1002.02683

12 H. C. Yen, S. Y. Liou, and Y. C. Hsieh: 2011 6th IEEE Conf. Industrial Electronics and Applications (ICIEA 2011) (2011) 306. https://doi.org/10.1109/ICIEA.2011.5975600

13 I. Seginer and I. Ioslovich: Agric. Syst. 62 (1999) 143. https://doi.org/10.1016/S0308-521X(99)00057-8

14 M. Takatsuji: Math. Control Appl. Agric. Horticulture 24 (1991) 81. https://doi.org/10.2525/jshita 1989.1.31

15 J. Hwang, H. Jeong, and H. Yoe: Adv. Sci. Technol. Lett. 49 (2014) 174. https://doi.org/10.14257/astl.2014.49.33

16 S. Cha-Um, B. Ulziibat, and C. Kirdmanee: Aust. J. Crop Sci. 4 (2010) 750. https://www.researchgate.net/ publication $/ 228500743$

17 T. Kozai, K. Ohyama, and C. Chun: Acta Hortic. 711 (2006) 61. https://doi.org/10.17660/ActaHortic.2006.711.5

18 D. T. Nhut, T. Takamura, H. Watanabe, and M. Tanaka: Acta Hortic. 692 (2005) 137. https://doi.org/10.17660/ ActaHortic.2005.692.18

19 Y. Li, H. Chen, H. Ji, S. Wang, Z. Zhu, and X. Wang: 2012 Symp. Photonics and Optoelectronics (2012). https://doi.org/10.1109/SOPO.2012.6270919

20 J. A. V. Magsumbol, R. G. Baldovino, I. C. Valensuela, E. Sybingco, and E. P. Dadios: 2018 IEEE 10th Int. Conf. Humanoid, Nanotechnology, Information Technology, Communication and Control, Environment and Management (HNICEM) (2018). https://doi.org/10.1109/HNICEM.2018.8666239

21 C. U. Suriyan, S., B. Ulziibat, and C. Kirdmanee: Aust. J. Crop Sci. 4 (2010) 750. https://www.researchgate. net/publication $/ 228500743$

22 Y. Li, H. Chen, H. Ji, S. Wang, Z. Zhu, and X. Wang: Symp. Photonics and Optoelectronics (2012). https://doi. org/10.1109/SOPO.2012.6270919

23 J. A. V. Magsumbol, R. G. Baldovino, I. C. Valensuela, E. Sybingco, and E. P. Dadios: IEEE 10th Int.Conf. Humanoid, Nanotechnology, Information Technology, Communication and Control, Environment and Management (HNICEM) (2018). https://doi.org/10.1109/HNICEM.2018.8666239 